
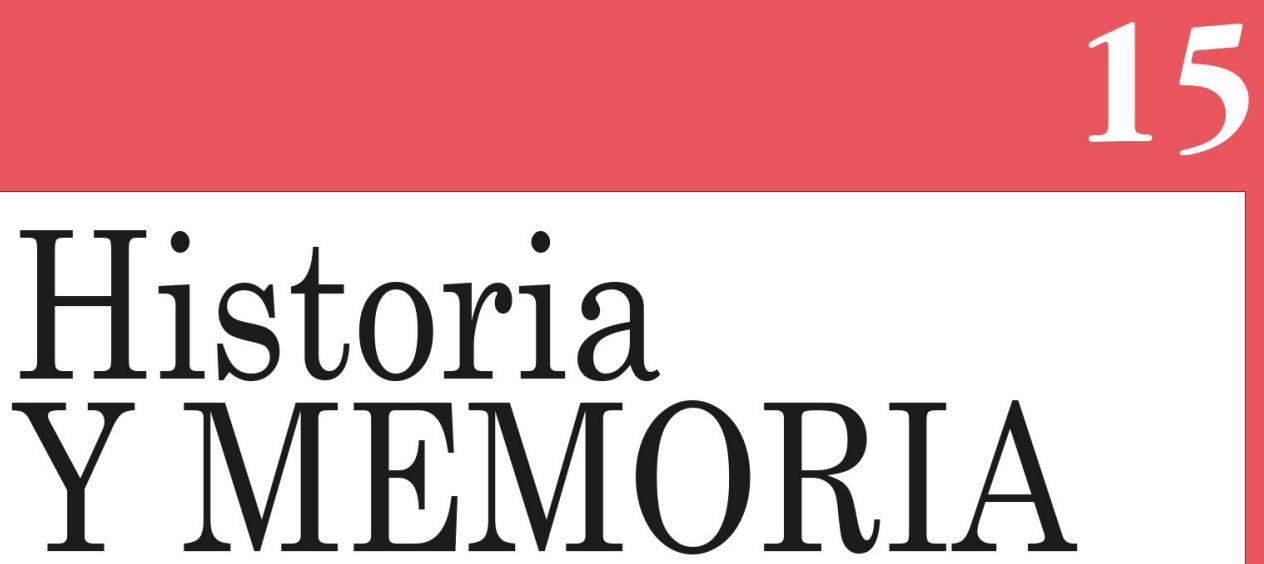

ISSN: 2027-5137 Julio - Diciembre, Año 2017 - Tunja, Colombia

La enseñanza de la historia y los métodos de investigación histórica no convencionales

https://doi.org/10.19053/20275137.n15.2017.6155

David Moriente

orcid.org/0000-0002-6746-3662

Páginas: 333-350

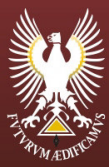




\title{
La enseñanza de la historia y los métodos de investigación histórica no convencionales*
}

\author{
David Moriente ${ }^{1}$ \\ Universidad Internacional de Cataluña-España \\ https://doi.org/10.19053/20275137.n15.2017.6155
}

Olga Yanet Acuña Rodríguez²: El conversatorio tiene como objeto generar un público lector alrededor de una serie de temas como el que plantea el profesor David Moriente, «la enseñanza de la historia y los métodos de investigación histórica no convencionales» el caso del arte, del cine y de otras estrategias que permita la difusión y apropiación de un saber, y conocer los métodos para la investigación histórica.

David Moriente: Lo que quería comentarles a este respecto es un poco retomando la idea de la conferencia; cuando me propusieron la celebración de este curso-seminario, supuso un reto porque de repente tuve que organizar urgentemente una cantidad de documentación y de posibilidades de uso de discursos y dispositivos que permitieran a los alumnos la adquisición de herramientas y, sobre todo, de mapas conceptuales como base para el aprendizaje e implementación en el trabajo como historiador, por lo menos en la práctica de la historia inscrita en el tiempo actual: porque, querámoslo o no, es el tiempo de las humanidades digitales, y obviamente

* Este texto es la versión ligeramente corregida del conversatorio sobre la conferencia dictada por David Moriente titulada «Métodos de investigación histórica no convencionales: imagen digital e internet» celebrada en el auditorio de Derecho UPTC-Tunja, el 11 de octubre de 2016.

1 Doctor en Historia del Arte por la Universidad Autónoma de Madrid; profesor de la Universitat Internacional de Catalunya y de Escola Massana Arts i Disseny. (iD) orcid.org/0000-0002-6746-3662

2 Profesora del Doctorado en Historia, UPTC, y editora de la revista Historia Y MEMORIA. 
la práctica de la desarrollado en este espacio tecnológico se orienta hacia la historia digital en una fracción considerable.

En este sentido, con toda esta masa crítica de documentación que había abocetado se dispusieron una serie de bloques. Un primer bloque, es el relacionado con lo tecnológico y la construcción de ese entramado invisible que es el Internet. Un segundo bloque referido a las posibilidades de enunciación que tiene Internet, sobre todo en las páginas web y en otro tipo de herramientas que aparecen como las enciclopedias digitales, en concreto "Wikipedia». Le seguía otra sección donde se hace referencia a la confrontación que existe entre nativos e inmigrantes digitales; $y$, finalmente, bloques instrumentales puestos en relación a cómo afectan las tecnologías de la información y la comunicación dentro de los procesos de enseñanza y de docencia.

Permítanme la expresión, un tanto tosca, de que "estamos en pañales todavía», en relación a cómo nos afecta tanto a los investigadores el trabajar con una herramienta y con un medio; de hecho, hay bastantes autores en la órbita de las plataformas digitales que se preguntan ¿cómo afecta Internet nuestra manera de percibir el mundo? Que básicamente [percibir e interpretar el mundo] es a lo que nos dedicamos los investigadores, y estamos tratando de explicar dentro de cada una de nuestras disciplinas ¿Sería la aplicación virtual de la res extensa en términos cartesianos? Por lo cual hay un montón de problemas de conceptualización que todavía hay que solventar, y dentro de la práctica docente es una de los ámbitos más idóneos sobre todo para explorar con los estudiantes, porque al fin y al cabo son nativos digitales y ellos aprenden de otra manera. Por ejemplo, estamos acostumbrados a ver niños de pocos años de edad que casi intuitivamente saben utilizar un dispositivo -sobre todo los táctiles- que parecen más connaturales al aprendizaje infantil. Todo esto, de alguna manera, en un futuro a medio plazo probablemente encontraremos nuevas maneras de percibir las interpretaciones en el ámbito de la investigación. Por ejemplo, las tesis doctorales que lleguen de estudiantes que hayan nacido en el año 2000-2010 nos van a sorprender 
no se sabe si para bien o para mal; desde luego va a haber un cambio de paradigma en ese sentido.

\section{Ronda de preguntas}

María Victoria Dotor ${ }^{3}$ Uno de los puntos que quizá más nos impactan es ¿cómo el internet nos está afectando y la forma como nos está impactando en la investigación histórica? Básicamente los historiadores provenimos de una disciplina fundamentalmente libresca, las fuentes primarias, los documentos y el texto físico es para los historiadores, es casi todo. Esta situación actual está planteando un giro y un cambio, al cual también muchos o bien no lo ven, o realmente no lo está asumiendo todavía ¿Qué significa esto para la investigación histórica y cuáles son esas transformaciones que avizora en estos momentos?

David Moriente: En el boceto inicial del curso, el primer bloque se titulaba "Apocalípticos integrados en la esfera tecnológica», en ese sentido evocaba a Umberto Eco. $\mathrm{Y}$ esto es importante, porque en los años 60, ya Marshall McLuhan vislumbró un interés por comprender los medios de comunicación; manifestando la tensión estructural que iba a haber en un futuro: la idea del objeto físico y los repositorios digitales.

Si bien en nuestra disciplina hay algo de arqueológico a la hora de meterse en las instituciones archivísticas, a «bucear» el medio; Internet lo que nos ha permitido es acceder a otros archivos, ha facilitado que investigadores de distintas partes del mundo pudieran acceder a archivos que de otra manera no podrían hacerlo. Sabemos los problemas que tenemos para investigar en general y más concretamente en humanidades, ya que tenemos mayores dificultades para conseguir medios de financiación; por este motivo, el hecho de permitir el acceso a las colecciones de los archivos — que ojalá fueran mucho más amplias y en determinadas instituciones, también tuvieran los fondos necesarios para fomentar un mayor número

3 Directora del Doctorado y Maestría en Historia, UPTC. 
de digitalizaciones - es sumamente importante para los investigadores que, por condiciones geográficas o económicas, no pueden acceder a ciertos archivos. En ese sentido, va a haber una transición -eso por un lado- y no creo que vaya a desaparecer el libro como objeto físico, e incluso como objeto de culto, por ejemplo: las colecciones bibliográficas; pero lo que si va a transformarse es la manera de narrar y de relatar sobre todo en términos de linealidad. Cada vez el documento escrito, por y para la red, se va a beneficiar de toda la narrativa hipertextual; al fin de cuentas, los textos son inherentemente hipertextuales porque se van refiriendo unos a otros, en lo que Michel Foucault denominó la «función autor». Así en términos de opinión -y no es ciencia- habrá un proceso desde el cual se van a ir imbricando los dos modelos.

Antonio E. de Pedro ${ }^{4}$ : Los archivos no van a sufrir un gran cambio, van a digitalizarse. Esto va a facilitar, más todavía, la información en primer plano. Pero lo que si va a cambiar, es la manera como los historiadores trabajan, eso va a cambiar radicalmente; de hecho ya cambió, lo que pasa es que en ciertas líneas de la historia no se dan cuenta del cambio. Los historiadores del arte o de la cultura visual, están un poco a la vanguardia de este cambio; y lo llevan haciendo hace mucho tiempo. No han sido unos historiadores que simplemente manejasen el texto escrito, ya jugaban con las imágenes, aspectos fragmentados de las imágenes y con los formatos; para ellos, ese cambio no es tan fuerte, es una consecuencia de lo que venían haciendo. Pero para otros historiadores que ni siquiera han llegado al nivel de que la imagen sea un instrumento documental, sino que la ven como simplemente un adorno y la utilizan de manera netamente ilustrativa, el cambio será drástico. Porque, lo cultural del texto digital es una cultura fractal y maneja elementos de composición a los cuales la linealidad se opone directamente, esto va a pasar con el trabajo de muchos historiadores. Ahora el nuevo historiador va a tener que acostumbrarse a manejar todo esto que alguna vez se hacía un «poco artesanal» y ahora

4 Profesor del Doctorado y Maestría en Historia, UPTC, coordinador editorial de la revista Historia Y MEMORIA y Presidente de la Red de Estudios Visuales Latinoamericanos (REVLAT). 
se hace cada vez más tecnificado: trabajar no para hacer textos en papel, sino para hacer textos en digital, que es una cosa muy distinta. Ahora estamos en una fase de transición todavía: hacemos textos en papel y luego los subimos a digital; eso va a desaparecer en muy poco tiempo. Es decir, estamos obligados a pensar en el contexto para una cultura digital. Y cuando pensamos en digital hay que pensar con una cabeza distinta, es decir: hay que pensar como un internauta, hay que pensar en mover al lector, hay que direccionar al lector, jugar con las teorías de la iconicidad y del vector, de toda esa línea de trabajo que está en semiótica como obra abierta, del working progress, todo eso tiene que empezar a trabajarse por los historiadores.

Los que trabajan con los procesos de construcción de textos lo van a tener mucho más difícil, porque no tenemos los borradores, y no podemos rastrear las idea iniciales en los borradores. Que hubiese sido de la filosofía si no tuviésemos posibilidad de rastrear en los borradores el avance de las ideas de un autor. Todo esto se verá afectado. Y tendremos que acostumbrarnos a trabajar con el texto final. Idea que también estará condicionada por el working progress; es decir, que nunca va a haber un texto final. La intertextualidad, la hipertextualidad, la hiperconicidad, todo este juego de cosas que estaba en la Semiótica, serán fundamentales para entender todo el proceso

Olga Yanet Acuña Rodríguez: El investigador histórico del siglo XX y de comienzos del XXI contaba con información limitada, ahora contamos con información que ha sido digitalizada; hay nos encontramos con dos apuestas: una la digitalizada, que de todas maneras mantiene una cierta estructura, responde a un texto escrito, a unas memorias y demás; y otro tipo de información que se tramite a través de la red, formatos, comunicaciones, informes y esquemas, de los cuales no queda ningún tipo de registro físico. Es decir, que nos encontramos con dos tipos de documentos digitales: el primero, el digitalizado que tiene su respaldo en físico y un segundo, digital que está expuesto a tramites, procesos y otro tipo de herramientas. Es una apuesta a la que los historiadores 
nos estamos enfrentando y nos tenemos que enfrentar, porque según nuestra percepción como historiadores: ¿hasta dónde considera que la información permanece, porque muchos de los discurso, del pensamiento, las ideas que se escriben y de discuten, no queda ningún registro?

David Moriente: Con respeto a estas inquietudes que formuláis estaba pensando en dos cosas, una, que realmente si echamos la vista atrás, todo esto tiene experiencias previas con ARPANET en los años cincuenta y sesenta. Internet tal y como lo conocemos los usuarios, existe como tal desde 1993; lo que quiero decir es que si miramos son un poco más de 20 años, y es muy poco tiempo para asimilar un montón de cosas para las que no estamos preparados todavía; eso por un lado. $\mathrm{Y}$, por otro, pensaba precisamente que como analogía viene bien, una de las tesis que manejaba Roland Barthes en $L a$ cámara lúcida. En líneas muy generales, Barthes mantenía la idea de que la parte que subyace o atrapa al observador de una fotografía - el punctum - lo trasladaba, en cierta medida, al momento y al lugar en que se había efectuado la imagen, compartiendo espacio con el fotógrafo. De ahí, privilegiaba la importancia del haber estado allí. Las tesis de presencialidad de Barthes se desmontan con el advenimiento de la imagen digital, generada sin necesidad de un referente físico, es decir, una imagen sintética que es indistinguible de una imagen real, un proceso icónico cada vez más frecuente en los filmes blockbusters de temática fantástica o de ciencia ficción, donde la indecibilidad del origen de la imagen se ha convertido en habitual; es decir, la imagen digital sirve, por ejemplo, para eliminar edificios que no obedecen a una época determinada (con el fin de evitar anacronismos) o para introducir a personajes o animales de naturaleza fantástica, y así en un largo etcétera. Reconduciendo esta idea a la cuestión de la práctica de la historia, y ahí creo que es donde se halla el desafío para los historiadores, va a ser el proceso de verificación de determinado documento, porque a través de todas las herramientas digitales podemos construir artefactos documentales que poseen apariencia veraz o efectos de verdad, como decía Michel Focault; en este sentido, va a ser tremendamente complicado establecer los procesos para la 
verificación. Todos nos habremos encontrado con «referencias fantasmas» - en ese sentido, Borges era un maestro a la hora de inventárselas - que no se podían comprobar, en un futuro muy cercano, pues, no es que solo nos podamos encontrar una «referencia fantasma», sino literalmente un «libro fantasmal» cuyas tesis, según como sean, pueden ejercer una influencia considerable; por lo cual en determinados ámbitos quizás sea un reto aún mayor.

Antonio Elías de Pedro: Es decir podemos crearnos un filósofo, un historiador de pasado, podemos crearnos cualquier protagonista, no solo un documento sino toda una historia de un sujeto que de repente puede aparecer con una historiografía "fantasma», con un estilo y una forma; eso ya se ha hecho en arte cuando crearon artistas que nunca existieron.

David Moriente: Estoy pensando también en el libro de Carlo Ginzburg, El queso y los gusanos, que para mí es uno de los mejores libros que se han escrito. Básicamente Ginzburg lo que hace es reconstruir el universo mental del molinero, estableciendo elementos verosímiles que dan la impresión exacta de la existencia del personaje del molinero Menocchio, juzgado por la Inquisición.

Antonio E. de Pedro: Aunque puede existir en un simple documento, una pequeña referencia que él tiene; todo lo demás, lo ha construido históricamente. Esa es una de las cosas importantes en el trabajo del historiador. Los historiadores "llenamos» las narrativas, porque trabajamos en narrativa. Ese intento descabellado de los estudios de los primeros Anales de denostar la narrativa fue un fracaso total. Hoy hemos vuelto a lo que ha sido la esencia de la historia: construir historias: los ingleses hablan de la story, la historia y la historieta. Construimos historias y eso hay que asumirlo. Ahora, el asunto está en que hay que superar una serie de tradiciones. Estamos ante un desafío maravilloso para poder manejarlo y va a jugar mucho la imaginación.

David Moriente: Estaba pensando en la posibilidad de que cada vez hay más páginas de información en Internet que 
nacen, crecen, se reproducen y mueren, ¿Qué posibilidades tenemos de dar fe de que he utilizado tal página y estaba pensando ya no en la nota a pie de página, sino en la imagen a pie de página? Es decir, utilizar dado que tenemos en enlace digital en vez de utilizar el enlace, ver la captura de pantalla de la imagen, terminaremos haciendo eso, porque evidentemente en papel no podemos hacer estas cosas.

Pero el formato digital nos permite enriquecer nuestro discurso, muchas veces había pensado la posibilidad de que mientras estoy citando un párrafo por ejemplo de Louis Althusser, me gustaría poner de fondo las revueltas de las calles en París, solamente para enfocar el sonido, y poner en contacto o conjugar dos documentos de muy diferente origen. ¿Hasta qué punto ese tipo de narrativa transmedia, intertextual no podría ser adecuada a nuestra práctica histórica?

Estamos acostumbrados a ver documentales y para los que dedicamos interés a su estatus ontológico, nos parece muy enriquecedor utilizarlos en la práctica docente. En un documental manejamos muchos formatos, podemos poner imágenes de archivo, podemos añadir entrevistas, música, entrevistas, etc., y eso mismo lo deberíamos intentar desarrollar dentro del formato de una hipotética escritura transmedia. Esa capacidad de exploración es lo que se vislumbra se pondrá en práctica en el futuro, de poder beneficiarnos de innumerables elementos que el simple papel no tiene capacidad de absorber. Evidentemente, la lectura en papel ofrece otro tipo de experiencias emocionales que son propias el individuo, es decir, leer un libro implica un determinado tiempo de desconexión con la realidad.

Antonio E. de Pedro: Nos vamos a encontrar con estudiantes que son analfabetas del papel y se convierten en lectores digitales. Ese tipo de lector tiene algunos problemas en relación a las tradiciones ¿es necesario haber pasado por la cultura del papel, haberse enfocado en la cultura del papel para poder pegar satisfactoriamente el salto a la digital? 
Ya no es solamente la lectura, ¿Cuántos van a dejar de escribir a mano? La mayoría ya no sabe; de hecho el paso de escribir a mano ha ido evolucionando, por ejemplo los de la anterior generación todavía escriben enlazado, crean una letra corrida, era lo normal, porque así nos enseñaban. Los de las generaciones posteriores escriben con todas las letras separadas y no las enlazan; y ya vamos a la tercera fase, que es que directamente ya no escriben a mano, porque en la universidad puedes mandar el texto al profesor vía internet y no escrito a mano. Eso va a crear un problema físico, los dedos de la mano están pensados para ciertas cosas, para usarlos. Ha sido producto de siglos de evolución, pero quizás, el dedo índice terminara siendo más puntiagudo y largo para digitalizar cada vez más en los aparatos tecnológicos.

Olga Yanet Acuña Rodríguez: Otro aspecto es el proceso cognitivo, cuando se escribe a mano se está desarrollando un proceso que vuelves a retomarse en el papel y de allí hay otro procesamiento de la información que a la vez es un proceso del conocimiento que dinamiza el aprendizaje, igualmente se fija una forma de memoria y se generan elementos para la reflexión.

Antonio E. de Pedro: Ya no piensan en el grafo, piensan en la imagen

David Moriente: Evidentemente no pensamos igual cuando estamos escribiendo con un teclado que cuando estamos escribiendo a mano, son procesos cognitivos y de organización de la red neuronal que son completamente distintos. Según estudios publicados hace poco en la revista Nature, se habla de una revolución en esos procesos cognitivos de y de adquisición de competencias lingüísticas, de ahí que los niños nacidos en los últimos diez años probablemente no pensarán como nosotros. A mis estudiantes les motivo a trazar mapas conceptuales, y les insisto en utilizar el papel, en dibujar y trabajar en clase con prácticas de 10 a 15 minutos, pues son muy operativas desde el punto de vista de la práctica docente, sobre todo porque obligan a pensar de manera diferente que sentarse a hacer un trabajo directamente con el ordenador, debido a que 
la escritura es mucho más inmediata, si se enfrentan al papel a hacer una serie de conjuntos, mapas, cartografía o como lo quieran llamar, en ese momento se está produciendo otro tipo de conexiones de conocimiento completamente distintas.

Con respecto a la lectura, no siempre se hace evidente que se pueden leer otros textos que no sean palabras. Muchos estudiantes - hablo en mi caso, como docente inscrito en el marco de la cultura visual- leen las imágenes, pero no saben que están leyéndolas, sobre todo los referentes en un mundo globalizado, transnacional, hipertextual, todos los adjetivos que queramos poner de la era posmoderna; en este sentido, los referentes se multiplican y proliferan hasta el infinito, y muchas veces ignoran su procedencia. De igual manera que la lectura de imagen se puede aprender, también aprendimos a leer los textos escritos a partir de Edad Media, en la que el saber estaba atesorado sobre todo en los grandes centros eclesiásticos, los monasterios. Gracias al trabajo de los copistas la proliferación de ejemplares permitió la distribución de los mismos dentro de las congregaciones; pero la manera de leer se dividía en dos procedimientos muy diferentes: una era la lectio, de donde proviene nuestra actual palabra lección, la mayoría lo que hacían era leer a un grupo de iletrados que eran los monjes, porque muchos de ellos sobre todo los legos no tenían conocimientos ni de lectura ni de escritura, entonces había un monje que pronunciaba la lectio que normalmente eran apologías que provenían de la Biblia, y generalmente en el refectorio durante las comidas. El otro tipo de lectura era la meditatio, de donde proviene nuestro actual término de meditación; evidentemente una meditación es una lectura profunda, mucho más elaborada. Así pues, la mayoría de los textos que se copiaban antes de hacer la exégesis o la glosa habían pasado por un proceso de meditatio. Salvando muchísimo las distancias, en la actualidad nos hallamos (tanto como usuarios como productores de conocimiento) en ese intervalo en el cual estamos pasando de un tipo de escritura y un tipo de lectura, que era la que estábamos familiarizados desde el siglo XIV con la gran proliferación de las ediciones impresas en Internet unido a la informática, a la cibernética y las tecnologías de información y comunicación. Todo ello ha 
sido una singularidad en el sentido de que no se podía prever el desarrollo que iba a tener Internet. Así, ahora estamos en nuestro propio proceso de pasar de la lectio a la meditatio, es decir, de sus equivalentes.

Antonio E. de Pedro: Ahora que hablamos que se produce una gran revolución, en el Renacimiento, con la aparición de la imprenta, esa revolución fue muy importante pero a nivel de divulgación del conocimiento, y no tanto con el conocimiento que es lo que nos está pasando ahora. Mientras que la de la imprenta no fue una revolución cognitiva, ya se inscribía, los monjes escribían, simplemente que los caracteres móviles de la imprenta permitieron la reproducción en serie, que fue muy importante para la divulgación. Desde la aparición de las tablillas en las ciudades babilónicas hasta la revolución de la imprenta, el proceso era uno: el uso de la mano; las palabras y combinación de las palabras; la creación del lenguaje escrito. Pero lo que ahora ocurre, está provocando una manera distinta de pensar, de conocer cosas y de acercarse a la realidad. Porque no es claro si la cultura digital es un instrumento, o es en sí mismo la realidad. Yo creo más bien lo segundo

David Moriente: Este tipo de conversaciones siempre son muy evocadoras de cosas que uno tenía por olvidadas y que, de repente, emergen. Jacques Derrida en «La farmacia de Platón» habla de la oposición entre habla y escritura, y de las connotaciones negativas de esta última en detrimento de la expansión del logocentrismo, porque la escritura es un pensamiento diferido, y, por tanto, es un apoyo para la memoria, Derrida inserta todo ello al hilo de la metafísica del presente y el texto establece los problemas de la escritura con respecto a los de la memoria. Así, se podría considerar una suerte de proceso apocalíptico con respecto a la escritura, porque la escritura se consideraba una especie de mala memoria; el hecho de que no pudiéramos utilizar la cultura oral, las letanías en cuanto a los árboles genealógicos, las experiencias de abuelos, bisabuelos, tatarabuelos, todo esa herencia memorística; aunque sabemos que en muchos sitios continua de alguna manera, ello está desapareciendo. Porque hasta en los lugares más remotos nos 
encontramos con pueblitos con un índice de analfabetismo practico (el problema de definir analfabetismo es hoy, por otra parte, un poco complicado), pero tiene una riqueza cultural en términos de cultura oral y están conviviendo con los teléfonos móviles, con el Internet, hay una serie de "cortocircuitos» que son bastante complicados. Esta idea de que la escritura era una mala memoria a lo mejor tiene que ver también con que ya no sabemos si el Internet es el medio, el mensaje o directamente el mundo. Lo que probablemente fue la intención cuando he utilizado la parábola que dictó Foster Wallace en la clausura del curso de Kenyon College, puesto que es muy significativa con respecto a que es Internet; por ejemplo, hay series de televisión como Black Mirror que inciden en nuestro comportamiento: ¿cómo fusiona la tecnología y cómo funciona la red en nuestra experiencia emocional colectiva? Interesan los procesos colectivos, porque de alguna manera son los que permiten comprender, aunque sea un atisbo, como afectan este tipo de cuestiones: ¿Cómo se aceptan los fascismos en un país?, tiene que ver con las experiencias colectivas; ¿Cómo afectan determinadas decisiones que se llevan a cabo en un Estado?, ¿cómo se construyen determinadas identidades nacionales? En este sentido, Internet es, desde luego, una experiencia colectiva. Neuromancer, escrita en 1984 por William Gibson, describe el ciberespacio como una alucinación colectiva, y es en este sentido que tenemos ubicar cada uno nuestros territorios; bueno, ya no son territorios fijos, pero de igual manera ocurren en las cartografías geopolíticas reales, ya que en los últimos cincuenta y sesenta años ha cambiado muchísimo todo esto, todo es work-in-progress.

María Victoria Dotor: En un momento surge necesariamente la idea en este periodo quizá de transición de que no necesariamente todo lo nuevo no es lo mejor y también un poco el cuestionarse: ¿si es realmente revolucionario o es un cambio método revolucionario frente al conocimiento? $\mathrm{Y}$ volviendo un poco al terreno de la disciplina histórica, cuando se habla del texto de Ginzburg es paradigmático en el sentido de que muestra ese nuevo método de la historia como representación; como creación en estos nuevos métodos vería al Internet como un perfeccionamiento o un estadio mayor en esa 
idea de la representación. Pero quizás es una profundización casi de la ficción de este nuevo lugar de la representación. No obstante, la disciplina histórica no necesariamente se diluye por el método, es decir la disciplina histórica siempre ha salido avante con elementos por ejemplo como la crítica de fuentes o la crítica documental, que vuelve y se tiene que trasladar a ese nuevo espacio o el análisis de esa masa documental que ahora es cuántica, etc., Vuelve y traslada sus métodos, sus posibilidades de análisis, evidentemente aparecen otras cosas que ya mencionaron como el uso más dinámico del texto, de la imagen, entre otras; Pero tiene que haber un momento de transición, donde nuevamente las herramientas que como disciplina se tienen la que da las garantías nuevamente de la «cientificidad», porque no vamos nuevamente a una discusión como la que inauguró la posmodernidad: todo vale y cualquier cosa va hacer el discurso y la narrativa histórica a través de este medio. Por otro lado, en nuestros contextos aun no estamos en matrix; aun las comunidades siguen existiendo; si bien tiene efectos, porque desde la red se convoca, se vive y se crea, también están los procesos sociales y las experiencias colectivas más allá de la web que evidentemente son el referente colectivo y que vuelve y se expresa, se suma. Están las experiencias colectivas de vida que pasan y eso va recreando y deja otras formas también de fuentes que no nos sumergen solamente en internet.

Antonio E. de Pedro: No todas las revoluciones son avance. Una revolución puede ser un retroceso. Pero la palabra revolución en sí, significa cambio, cambio de paradigma; y también utilizando la expresión de idiolecto que decía Umberto Eco, no hay ningún idiolecto radical del todo siempre hay una huella de eso para hacer las revoluciones; o sea las revoluciones no rompen absolutamente con todo; por ejemplo, si algo hemos aprendido de todo este proceso, es que eso que llamamos realidad es un constructo. No existe la realidad como algo exterior a nosotros. Nosotros como sujetos individuales y colectivos somos los que construimos realidades. Si todavía no hemos asimilado todo esto, estamos en riesgo, porque lo que está pasando en estos momentos es que la realidad se quitó el disfraz de la apariencia, por decirlo abruptamente. Es decir, 
la realidad ya nos está enseñando todo lo que es ella que es ni más ni menos que un juego de lenguajes, de constructos, etc. Tenemos que movernos de otra manera, porque evidentemente está en función de muchas cosas, la supervivencia humana, del planeta, de los animales, muchas cosas que están en juego. Sí no aprendemos a manejar esas herramientas, sí seguimos creyendo que trabajamos con el disfraz, estamos en peligro porque el disfraz ya no es válido; la apariencia desapareció, nos hemos encontrado con la verdadera realidad como meras representaciones. Es importante que lo aprendamos rápido, porque vienen muchas cosas. La era robótica está a punto de eclosionar a todos los niveles de nuestra vida cotidiana, ya no en la empresa donde ya está instalada, sino en nuestra vida cotidiana. La robótica y la inteligencia artificial van a estar ahí, y vamos a tener que funcionar con ella. Y va haber países que se van a dedicar a hacer robots y van a vivir en ese tipo de cultura. Esta generación de jóvenes van a tener que jugar de otra manera el partido, porque ya tiene otras reglas y tenemos que conocerlas bien por muy duras que sean, porque, ya lo dije, lo que se juega es mucho en el sentido de lo humano. Todo este tipo de cosas hay que tenerlo en cuenta. Toca decidir, porque el sistema capitalista, que es el triunfador y está en su fase neoliberal-tecnológica avanza, nos martillea.

Olga Yanet Acuña Rodríguez: Queda una reflexión en algo que David Moriente ha planteado y es que hay tres etapas básicamente en una crisis, una crisis en términos de la oralidad. La escritura sigue estando pero de otra manera, mientras que la oralidad va desapareciendo casi que en todos los escenarios, es una transformación abrupta tanto en la cotidianidad y en aquello que María Victoria señalaba sobre las tradiciones que también van desapareciendo, porque los jóvenes están ligados a su computador y a su celular; aspecto que se ve desde las familias más humildes en nuestro medio, hasta las que tienen mejores condiciones económicas. Todo el mundo está con su celular, y no es la cultura de hablar sino del mensaje de texto o de estar en el Internet. Puede que se esté en grupo, pero cada quien está pendiente del mensaje de whatsapp, del correo, etc. La memoria y la oralidad se van a transformar. Formaba parte de las tres etapas de la tradición 
junto con la escritura, y la cultura visual; y es la cultura visual la que prevalece.

Antonio Elías de Pedro: La cultura visual no son solamente las imágenes tradicionales, son los textos escritos subidos a Internet convertidos en imágenes.

David Moriente: Para conectar las reflexiones con estos comentarios hay que verlo en términos de mutaciones, no me refiero tanto a las mutaciones epistemológicas de las que hablaba Michel Foucault en La arqueología del saber, sino mutaciones en términos evolutivos. Si tuviéramos que hacer una analogía, serían los neandertales vs. los sapiens y en ese proceso de mutación obviamente los sapiens y los neandertales eran prácticamente iguales, pero los sapiens eran una mutación superior, o sea eran como una especie de "superhéroes» en comparación con los neandertales. Hay un problema en el cual cortocircuita a todos nosotros porque estamos intentando comprender algo que se nos escapa, en ese sentido hay una dificultad sobre todo con las cuestiones de representación. El mundo es evidentemente representacional y siempre estamos intentando traer al presente —otra vez la idea de la metafísica de la presencia que ha contaminado toda la historia de Occidente. En un mundo globalizado donde la idea de Occidente se ha extendido incluso hasta Oriente, esta metafísica de la presencia de alguna manera está intentando empujar hacia la poshistoria, que, en efecto, es lo que buscan realmente las posiciones neoconservadoras y ultraliberales: el hecho de que no exista una Historia. En esta misma línea hay un proceso en el cual la oralidad se pierde en pos de la construcción del avatar que está en la red social: Facebook, Twitter, Instagram, etc., son todas construcciones ideales de un auto-yo que no existe. En algunos de sus pronósticos Slavoj Žižek habla de la realidad como el mundo digital de las redes sociales y que aquello es algo imparable ya. En lo concerniente a la práctica de la Historia, resulta obvio que va a continuar, pero completamente mutada; o sea, no es que se vaya a diluir sino que se va a convertir en otra cosa. Entonces, nosotros que estamos inscritos en este mundo transicional donde, personalmente, me encuentro entre dos generaciones 
por así decirlo, una me ancla a la tradición, y la otra soy una persona que cuando estoy trabajando utilizo dos pantallas, puedo usar dos ordenadores a la vez, junto con una tablet o un smartphone, estoy completamente conectado y no me produce ningún problema cognitivo. En este contexto es donde se halla la mutación.

Antonio E. de Pedro: Es un tema apasionante y un reto para universidades como la UPTC en que muchos colegas no están en este debate. No hablo de colegas que están a punto de jubilarse, sino de gente de cuarenta años que está inmersa en todo esto, y que creo no son conscientes de lo que está pasando.

David Moriente: De hecho el discurso, el discurso institucional utilizado en los mítines y otro tipo de reuniones, más o menos públicas, y luego el discurso vía Twitter.

Antonio E. de Pedro: Es una especie de privadocolectivo, o sea la categoría privada y pública ha desaparecido; pero se están creando otras categorías que no se saben si son privado-colectivo o público-individual, hay una serie de hibridaciones.

David Moriente: Es una generación de opinión, pero que es una opinión de un cuerpo que no es tangible, un cuerpo que es colectivo. El yo digital se permite determinadas libertades que el yo físico, en condiciones de contexto real, no se permitiría. Hay discusiones que jamás habría pensado que iba a tener con personas que consideraba amigos, pero discusiones muy encendidas, o sea dejar de tener la amistad por cuestiones en Facebook, que jamás hubiera llegado a pensar, pero en las que interviniesen la ideología. Quiero decir que cada uno toma una posición de resistencia y los enfrentamientos pueden llegar a ser bastante fuertes; hay personas que conoces desde hace veinte o treinta años que se hacen amigos luego en Facebook, pero esa amistad que hayas podido tener en esos veinte o treinta años -y digo compañeros de colegio, de escuela, de universidad, etc.-, tienes una relación cordial, gente con la que te juntas y además 
siempre hay un mismo proceso de experiencia interpersonal, pero realmente te has perdido la experiencia y el mecanismo por el cual esa persona se conduce en la vida. De repente, te encuentras con una sorpresa, y, evidentemente, todo esto tiene que ver con cuestiones ideológicas y de construcción del sujeto político. Resulta interesante en términos afectivos e incluso de psicología social: ¿Cómo afectan este tipo de cosas y sobre todo a cómo nos comportamos públicamente? Porque es evidente que hay una suerte de variación diastrática, en la medida en que se utilizan unos registros de comportamiento, evidentemente no te tratas con la familia, padres, hermanos, compañeros de trabajo, alumnos, estudiantes, etc., pero es que la trasformación en el avatar de Internet o, mejor dicho, de Facebook es completamente desmedida de gente que es muy incendiaria en las redes sociales y probablemente en la vida real no sería capaz de afirmar o sostener determinado discurso.

María Victoria Dotor: Esoes una delas particularidades de esa forma de comunicación y es que se permite ciertas libertades. Estaba pensando por ejemplo Danton cuando estudia las formas de difusión del libelo a finales del siglo XVIII, y noto que no todo era texto político, sino pornográficos o de cualquier tipo de opinión, y el texto político era un margen reducido, incluso el otro, el pornográfico tocaba con lo político.

Los medios y los lugares donde se recrea todo este mundo, dijéramos, un submundo y se cuestiona: ¿estás serán las fuentes del futuro?; por ejemplo, el Facebook, es allí donde realmente el debate político de la opinión publica cotidiana, es libre; o sea, de alguna manera la gente está diciendo su opinión como cree y como siente realmente. Finalmente se vuelve el lugar donde se pueden percibir esos sentimientos de la gente en su momento.

Antonio E. de Pedro: Son unas «micro-ágoras» públicas en las que se grita a todo el mundo, o se guarda silencio, sobre lo que le dé la gana, y se pude comportar políticamente correctos o incorrectos. Facebook es un poco subliminal en el sentido de lo sublime kantiano: si viviésemos el terror realmente no 
podíamos disfrutarlo. La pantalla de Internet es el asiento en la butaca del cine mientras vemos la supuesta película de terror, y lo podemos gozar. El placer de decir siempre he deseado decir esto y lo voy a decir.

Olga Yanet Acuña Rodríguez: Además, también está ligado a otro problema que es el sensacionalismo. Se puede inventar una catástrofe, se va acabar el mundo, y lo leí esta mañana en tal prensa. Una prensa inventada que no existe y que empieza a circular y empieza a generar pánico. Es otra apuesta. Hay que leer esa otra parte psíquica dentro de la construcción discursiva y las construcciones de unas representaciones simbólicas. 